\title{
4 Narrative, Identities, and Experiences in Discourse Practices of Migrants
}

\author{
Anna De Fina, Anne Golden \\ and Ingebjørg Tonne
}

\section{Introduction}

The study of narrative has fascinated scholars in many different areas of the social sciences, including linguistics, psychology, social work, history, and sociology, as it provides one of the most powerful tools to convey and shape human experience. Indeed, for researchers interested in understanding the intersections between language and social phenomena, narrative opens a window into identities, ways of life, moral systems, learning practices, ideologies, and all kinds of cultural constructs. Narrators build story-worlds in which they or others act as protagonists and/or antagonists. By doing so, they also present specific causalities and temporal connections between events, which project certain interpretations of those events. By placing themselves and others within story-worlds, they also choose categories related to agency (such as victims, perpetrators, and more generally, agentive or not agentive roles) (Bamberg 1997) and belonging (such as ethnicity, age, race, or origins), which afford a glimpse into ways in which narrators perceive social roles, social groupings, and their relation to social actions and the emotions evoked (Relaño Pastor 2014; Van de Mieroop and Clifton 2012). Often constructions of identity in narratives are shaped by - and in turn help shape and reshape - common understandings about typified social personas and situations. These links between narratives and identities have been recognized and investigated by many scholars in sociolinguistics and discourse studies (for a detailed discussion see De Fina 2015). Such investigations have greatly contributed to knowledge about migration as a process and immigrants as individuals and groups, which often undergo emotionally charged experiences.

In this chapter, we focus on the ways in which narrative as a tool for research and analysis has contributed in our own work to illuminating issues related to identities constructed and deployed by migrants and related to their multilingual practices. We embrace a context-sensitive and practice-based orientation to the study of narratives, and we show how this approach can shed light on new and interesting aspects of migrant identities by studying two different groups in two specific contexts: undocumented 
youth in the United States and adult language learners in Norway. In the study of adult language learners in Norway, we illustrate how a practiceoriented analysis can be used in research on second-language trajectories of learning through narratives elicited in a focus group, a context in which participants and researchers develop an open and intimate dialogue. We discuss how the migrants' different learning contexts and negotiations of identities are expressed in dialogue with the researcher. In the study of undocumented youth in the United States, we highlight how a practice-oriented approach to narratives allows researchers to put forth highly nuanced views of migrant identities. In particular, we show that through the investigation of narratives as embedded within communicative practices, researchers are able to point to the inventories of identities that are deployed by migrants in specific communities, thereby illustrating the ways in which such identities emerge, are embedded, and are negotiated in context as well as escaping essentialist views of who migrants are. We start with narratives from a group of young, undocumented immigrants in the United States.

\section{Narratives and migration: A practice-based approach}

In the study presented in this section, we highlight the importance of advancing investigations of storytelling practices among migrants in everyday, nonconversational contexts, therefore identities as emerging in action. Before presenting the study, we will briefly review research on migrants and identity within discourse studies and sociolinguistics as well as revisit the main tenets of narrative as a practice approach to stories.

Past research on identities has focused mostly on self-representation and other depictions in discourse produced by mainstream media, by representatives of dominant political ideologies and majority groups, or by the migrants themselves in interviews and focus groups (for a review, see De Fina and Tseng 2017). In the case of public discourse on migrants, investigations of news stories have illuminated the ways in which tropes and stereotypes about migrants are circulated in political discourses and in the media (see, for example, Busch and Krzyanowski 2012; Charteris-Black 2006; Gabrielatos and Baker 2008; Zhu 2014; Simmons and LeCouteur 2008), where they are portrayed through negative metaphors and tropes, related to criminality and ignorance, and compared to animals and floods. Other work investigating everyday narratives and accounts (Perrino 2019; Gotsbachner 2001) has revealed that people who belong to dominant and majority groups in different parts of the world often depict the same negative positioning about migrants found in the press, portraying them as criminals or unwilling to work, while at the same time ideologies diffused in public discourses, such as those that place on migrants the responsibility for integrating, are often taken up by migrants themselves (Cederberg 2014).

The literature on self-representations is very vast, including work on representations in interviews, focus groups, and written texts. Scholars have 
investigated how much and to what extent different groups of migrants present themselves as agentive protagonists of their lives or as victims of circumstances (De Fina 2003; Baynham 2006; Golden and Lanza 2013a; Miller 2014; Relaño Pastor 2014); how they perceive their own social inclusion or exclusion in relation to language experience (Barkhuizen 2013) and racial prejudice more generally (De Fina and King 2011; van de Mieroop 2012; Hatoss 2012); as well as the many ways they define their national, ethnic, and territorial belonging (Clary-Lemon 2010; Liebscher and Dailey O'Cain 2006; Archakis 2016). Studies often take an interactionist approach to narratives, looking at positioning processes rather than merely at the discourse of migrants and, in some cases, reflecting on the co-construction of experience that takes place through the contributions of all participants to storytelling. Regarding narratives as discursive and interactional practices is particularly important for the development of the field of migration studies. Therefore, it should be extended to other contexts beyond the interview and other kinds of interactions, such as the investigation of semiotic processes and practices that take place in domains and situations that include both migrants and members of local communities.

Before we present the first study, let us briefly summarize what we see as some fundamental ideas behind a narrative-as-practice approach. Alexandra Georgakopoulou and Anna De Fina sketch the main principles behind this orientation, called "social interactional" (see De Fina and Georgakopoulou 2008; De Fina 2021). The denomination reflects the combination of a close attention to the details of local communication with an awareness of the social, historical, and cultural connections that link storytelling practices to other semiotic practices and a variety of contexts at different scales. The concept of practice captures the habituality and recognizability of meaning making within communities - including the use of genres and the recourse to chronotopes (Bakhtin 1981, 84), that is, well-established and socially recognized frames involving specific time-space-identity connections (Blommaert and De Fina 2017) - while also pointing to emergence and transformation as inherent to social action. Thus, from this perspective, identities are built and negotiated within plural and often conflicting contexts as people simultaneously participate in different communities. Fragmentation, plurality, and emergence are central notions here, as opposed to homogeneity and continuity, especially as sociolinguistics starts to incorporate the notion of transient (Mortensen and Hazel 2017), virtual, and light communities (Blommaert and Varis 2015) together with the traditional construct of speech communities and communities of practice. Indeed, sociolinguists recognize that being rooted in the same geographic place or social category does not necessarily define a linguistic community, and communities sharing linguistic and semiotic resources may be formed around emergent practices and then disappear. A practice-oriented approach also involves proceeding from the bottom up through an ethnographic methodology. Hypotheses are formed from close observation of how different communities organize their 
storytelling activities, who produces the stories, who receives them, and how they are circulated. In the case of interviews or other interactionally based research, as we will see in the second study, a practice-based approach also implies a heightened attention to researcher reflexivity on the research process itself and the situation of communication with informants (see De Fina and Perrino 2011).

This kind of practice orientation can open up a new understanding of transnational and migrant individuals and groups, both as they communicate with each other and as they establish links with others. In the last decade work focused on new contexts for storytelling practices among migrants has already started to emerge. For example, a study on how space and spatial movement is incorporated into talk about self by migrants during "walk alongs" (see Sabaté i Dalmau 2015) reveals ways in which these mobile individuals define themselves and create boundaries around specific safe spaces. Research on online practices of migrants, ex-refugees, or generation 1.5 youth, including digital stories (Alexandra 2008), instant messaging (Yi 2009), and social media engagements (Baran 2018; Evers 2018), has also opened a path to nuanced understandings of the ways in which different groups express and negotiate belonging with their peers within close-knit groups.

Here we will draw some reflections from a project involving a study of online storytelling practices by members of the Dreamers movement in the United States within a context of political activism (for details, see De Fina 2020 ) in order to show how research on narrative that is practice-oriented and pays close attention to contexts and participants can deepen our understanding about identity processes and reveal their complexity. Dreamers are young migrants who came to the country with their undocumented parents and stayed over a period of years as undocumented individuals.

The Dreamers movement was born in 2008 when young migrants sought to convince Congress to enact legislation to protect migrants. Since then, it has become a significant grassroots movement involving almost half a million registered participants in 25 states (Nicholls 2013). It is interesting to see the kinds of images of themselves the Dreamers presented through social media, as well as the tools they used to build images, the different forms of story production on media, and how stories were shaped by the audiences to which they were directed. Two studies were conducted - one in 2015 and one in 2017 - in order to assess whether changes in the political landscape, specifically the advent of the Trump government, affected the way Dreamers presented themselves. The two studies compared identity presentation in autobiographical stories. In the first case, the narratives were video biographies from the Obama era posted on the movement's website. In the second case, they were autobiographical stories posted on Medium, a digital magazine and online blogging platform accessible through both free and paid subscriptions that publishes posts from a variety of organizations. The narratives were analyzed in terms of segments defined by topic (for example, 
the presence of demographic information or a "crucial moment" when undocumented status was exposed), in terms of moral stances expressed by the narrators through linguistic indexes, and in terms of the kinds of visuals presented in both the videos and the photographs accompanying stories. In the stories on Medium, hashtags and repetitions across stories were also taken into account.

For the Dreamers, storytelling is embedded and imbricated within a variety of other practices, and it is a centerpiece of their activism. By paying attention to the varied semiotic activities that are linked through activism, it is possible to see the interplay between "conditions of production" (who creates the stories, in what medium, with what affordances, and for what kinds of audiences), conditions of circulation (where are the stories told or posted), and conditions of reception (who has access to the stories). This kind of analysis has important implications for the way we understand identities. Thus, the personal video narratives that constituted the first corpus from 2015 were told by different individuals ( 2015 corpus). They were also highly curated since they were solicited and edited by members of the United We Dream (UWD) organization with the objective of convincing President Obama to enact new legislation in favor of undocumented migrants and getting people to take action. This made the personal video narratives relatively homogeneous in terms of the themes and strategies used to argue in favor of migrants, although the fact that the narratives were embedded into arguments also made them hybrid in terms of genre. In the narratives Dreamers shared details about their families and about how they arrived to the United States. Some narratives emphasized the narrators' lives and trajectories, some focused more on the parents' histories or how parents' dreams were crushed, and yet others devoted space to the reasons for individuals' activism. Because they were grouped together in a specific space on the website, these narratives had another layer of unity that helped form a collective message. What was found to be prevalent in those stories was the construction of a non-threatening persona, a kind of "good immigrant" image, which was fostered through the themes touched upon by the narrators when telling of their lives; visual elements, such as photographs or the environments in which narrators were filmed; and other semiotic components, such as musical accompaniment. This persona was highly functional to the aim of showing the President and the general public that young immigrants were "deserving" and assets to society because they possessed desirable qualities. At the same time, the narratives sought to stir the interest of possible future members of the movement by highlighting how activism changed the lives of many of the featured narrators, giving them a reason to live and be hopeful.

The second group of stories were all autobiographical narratives posted on the Medium platform under the UWD logo between 2016 and 2017 (2017 corpus). Some of these biographies were also reposted on Facebook. Compared to the stories published on the UWD website, this group of narratives present a clear picture in terms of production, reception, and 
circulation. Medium is a relatively closed platform, but it still has millions of readers and a potentially wider, more varied audience than the UWD website. In terms of production, the narratives published on Medium were clearly curated, meaning they were reviewed or even rewritten by UWD activists. Indeed, even though they are written in first person, often the photos accompanying narratives are labeled using third-person references (e.g., "X with her parents"). Because the narratives on Medium were not directly elicited in relation to a campaign, they do not feature the homogeneity found in the 2015 corpus of video narratives. Not only are the formats and contents of the Medium narratives more varied than in the 2015 corpus, they also make more room for the expression of negative and conflicting personal feelings like anger and frustration. In some narratives students talked about how they had achieved their educational aims. Others focused on the present moment and the impact of Trump's presidency on their lives. Finally, some featured more traditional life stories. This second group of narratives is constituted of hybrid stories combining narrative sections and arguments. Thus, possibilities for building a collective positioning in these texts are related to the incorporation of slogans, such as "Not this time," and hashtags, such as \#HereToStay or \#nobannowallaids, across narratives, which create intertextual links with other actions and stances expressed by the movement.

The collective identity that emerges in the narratives from the second period (2017) incorporates many of the elements of the "good immigrant" image discussed in relation to the video narratives. However, it also includes a stronger "activist" self-construction, with shades of being combative and uncompromising. Space constraints prevent us from presenting examples of full narratives, but differences beween the narratives on the UWD site (2015 corpus) and on Medium (2017 corpus) can be seen. For example, the conclusions have a different tone even where the theme is similar (e.g., parents' situation). While the narrators in the following examples both discuss family, note that the UWD website (2015) narrative includes an appeal to President Obama. ${ }^{1}$

\section{Corpus}

I think I will tell him [President Obama] that my mom just like all all mums deserves deferred action she deserves the same chance that I have been able to get in life so she deserves to be able to live without fear she deserves to be able to fulfill her dreams and for my mum America is her home she really has no plans to go back or living though this is where she wants to stay and this is where she should be allowed to stay 


\section{Corpus}

I continued to fight for our communities. I fight for the vision and hope of liberation for the undocumented community. My mother and my loved ones deserve a life without fear and with dignity, and I will not stop fighting until all of the undocumented community are liberated.

\#HereToStay

Both similarities and differences in identity construction and presentation remit us to contexts at different scales (see Blommaert 2015), ranging from more general to more local/particular. One scale is bounded by present time: it is the scale of general, repeated, and widely shared ideas and prejudices about who migrants are, what their role in society is, and more generally the qualities and predispositions that are desirable for those who belong to the community of United States citizens. A second scale refers to the political moment: the political climate at the national level, present battles being fought among social groups, and the kinds of organizations that movements put in place. The 2015 political environment was such that reform and the advancement of migrant rights appeared possible; in 2016-2017, however, the climate had changed with the advent of Trump, and high anti-immigrant tensions were in the air. A third scale involves the conditions of local production, including authorial roles; the format and kind of narratives that make it onto platforms, such as the one curated by UWD; the extent to which different individual voices penetrate various media; the affordances media have for conveying voices; and the audiences expected to access media. Finally, a fourth scale involves individual choice, whether it be the register, images, or story organization. No matter how curated a narrative is, there is also always a person talking in these stories.

When we look at all of these different factors and scales, a very complex picture emerges. We can clearly see that the identities constructed through narratives are embedded within many different contexts, which interplay with them. The level of granularity employed in making sense of narratives also determines the kind of picture that is produced. If we look at collective identities, then there are clear trends in the inventories of identities that were deemed relevant by the UWD movement. However, if we focus on the stories of specific migrants, then we see a much wider spectrum of identities in terms of degrees of agency, responsibility taken for one's life, degrees of optimism or pessimism regarding the future, degrees of identification with a combative or activist stance, emphasis on specific ethnic or religious affiliations, and so forth. The narratives reveal how different factors can impinge on the construction and negotiation of identities through narratives, while at the same time they can give access to a wide inventory of identities and of narrative strategies to present them.

In the next case study discussed in this chapter, the focus is on the coconstruction of narratives by a different group of migrants in a different 
context: namely second language learners in focus groups. Conversation is seen as a meaning-making practice that illuminates individuals' learning processes, showing how they build and negotiate their identities alongside other participants in a context of migration, including inviting the other participants into emotionally loaded events in the learning process.

\section{Elucidating emotions and language-learning experiences through narratives}

Since the turn of the century, language-learning memoirs and autobiographical interviews have been used by researchers to understand how L2 learners experience and make sense of language learning and educational matters in a new country. The stress on collecting personal experiences may be seen as a response to several researchers' underscoring of the powerful relationship between identity and language learning (Norton and Toohey 2011) as well as Norton Peirce's early call for a "comprehensive theory of social identity that integrates the language learner and the language learning context" (Norton Peirce 1995, 12). The study of language learners' narratives has contributed to new images of learners, who are presented not as "unidimensional abstractions" (Pavlenko 2007, 164) but as human beings with feelings and the ability to exercise agency in the learning process (Kanno 2003; Pavlenko and Lantolf 2000). Pavlenko $(2001,167)$ made a strong claim for integrating narratives in second language acquisition (SLA) research:

L2 learning stories ... are unique and rich sources of information about the relationship between language and identity in second language learning and socialization. It is possible that only personal narratives provide a glimpse into areas so private, personal and, intimate that they are rarely - if ever - breached in the study of SLA, and at the same time are at the heart and soul of the second language socialization process.

The aims of narrative studies in SLA research vary. Some examine differences in learner beliefs and learning strategies (e.g., Kalaja and Barcelos 2003), some study affective factors (e.g., Pavlenko 2006; Pavlenko 2013; Kramsch 2009; Prior 2011; Relaño Pastor 2014), and others analyze agency and identity constructions (e.g., Kanno 2003; Norton and Early 2011; Miller 2014). In several studies, language learners reveal through their narratives that they possess an arsenal of multilingual practices, thereby providing insight into their learning experience. Data can be collected through literary autobiographies, diaries, classroom assignments, and audio-recordings. Pavlenko (2007, 165), inspired by Denzin (1989) and Nekvapil (2003), classifies narrative studies within applied linguistics into three categories based on the type of information that researchers collect from the narratives: (1) subject reality, where researchers are interested in the narrators' experiences and familiarity with certain phenomena or 
events; (2) life reality, where researchers are interested in what has actually happened in the narrators' lives; and (3) text reality, where researchers are interested in how events are told, i.e., how the narrator positions herself or constructs different identities through the narrative. Pavlenko points out that the three approaches partially overlap. She situates herself in favor of the latter approach by pointing out that narratives are primarily discursive constructions (Pavlenko 2007, 181). In our narrative-as-practice approach (De Fina and Georgakopoulou 2008; De Fina 2021), we see these three aspects as intertwined. Indeed, in the analysis of the second case, we are concerned with text reality. We are interested in how the narrators position themselves or construct different identities through their narratives, as well as how they are constructed by (signifying) others in the language-learning process. However, we also focus on subject reality (i.e., the circumstances of the narrators' lives) and life reality (i.e., the types of actual events experienced by narrators and what they highlight as being decisive for their emotions).

In language-learning research it is not common to gather data about learners' experiences in focus groups, where the co-construction of narratives is evident (although some of the studies in the SKI project, e.g., Golden and Lanza's work, are exceptions). ${ }^{2}$ The advantages of encouraging narratives in such studies is clear. As the stories emerge, both the learners and the researchers reflect on different parts of their stories and make meaning about a complex learning process, where identity, agency, and belonging are central.

In the second case study, two migrant doctors, Nadia and Milena, together with a researcher, "A," participated in a focus group in A's apartment. Nadia was originally from a former Soviet Republic, and Milena was from an Eastern-European country. They both came to Norway in the mid1990s to get married, although Milena had visited Norway prior to that time. ${ }^{3}$ Both learned Norwegian as adults in Norway. In the focus group conversation, the two compared their life trajectories and discussed the expectations, frustrations, and joys they experienced during the time their home countries and attaining their present positions as well-settled medical doctors in Norway. Their language learning - in and out of the classroom - was a recurrent topic. We show how their narratives provide insights into how learning is experienced by learners of Norwegian. Such experiences are emotionally charged, even for very successful learners.

The elucidation of emotionally charged data, which is interesting for illuminating the language-learning process, is made possible here through a focus on the co-construction of narratives in the interaction involved in the focus-group context. The interactional perspective is important. Such accounts are recipient designed. Recapitulations of past events are constructed in response to explicit or implied why or how questions asked by an interlocutor (De Fina 2009, 240). In this way they are dialogic - they "shape and are shaped by the different contexts in which they are embedded" (De Fina 2009, 233). 
In the storytelling context of the second case study, researcher A starts out by telling the participants about the SKI project, which was the reason why the two learners were invited. She then positions the participants as resourceful by saying, "It's very interesting to talk to someone like you, who is highly educated and very reflective." ${ }^{4}$ Subsequently, A invites them to freely share their views of and experiences with migration, learning a new language, and encountering a new culture. At the same time, by indicating that participants' experiences and reflections are valuable, A positions herself as somebody with power, for example the power to influence school authorities. The importance of the context where the narratives play a central part becomes evident at the very end of the conversation. Nadia exclaims, "Wow, today was very exciting!" Then Milena suggests that the title of the study should be "Scheherazade," which highlights the significance of both their stories and storytelling.

Both Nadia and Milena came to Norway to meet and live with their husbands. However, as seen in each participant's opening remarks, their realities and experiences were complex and contrasting. In response to the invitation to share her views of and experiences with a new language and culture, Nadia starts out in a somewhat unexpectedly open way, which explicitly shows a high level of confidence in the (Norwegian) researcher:

\section{Excerpt 1}

Nadia: I don't know if I can be completely honest [...] I was a postal bride $[\ldots]$ a bride, yes? I met my spouse via correspondence.

A: $\quad$ Yes.

Nadia: Yes. This I usually do not say to Norwegians.

A: No,no@@@. That's fine. [...]

Nadia: But the fact is that I am one of those who come, yes.

A: $\quad$ But did you meet him (..) he announced?

Nadia: Yes, I didn't really advertise here, but in Sweden. It's actually very 'dirty business' (said in English). [... It is very embarrassing to say this@@@. Therefore, it is nice that it is anonymized.

A: Yes.

Nadia refers to herself as a postbrud (postal bride) when explaining how she came to Norway. In Norway in the 1990s, postal brides were seen as a low-status category of women viewed negatively for being willing to "sell" themselves to a husband. By revealing and sharing her personal history in the focus group, Nadia constructs herself as vulnerable, yet brave and confident. She discloses something that she usually hides. By laughing and admitting that it is embarrassing, she disowns her action and constructs herself as somebody with values other than those put forth in stereotypical Norwegian discourse of the time: "foreign" girls advertising for husbands were dishonorable. She negotiates a strong degree of agency by admitting 
that this action was central to her migration. In a subsequent narrative part she further explains her rationale for relocating: in her home country medical doctors are paid very low salaries. By pointing to her professional history, she constructs herself both as a hardworking person and an idealist. In her country of origin, she says, the medical profession "is the profession for idealists."

Milena, in contrast, starts by telling the story of her first trip to Norway to see her brother, who was a political refugee. She explains that her visit was instigated by her mother's sudden death. Her brother had not been allowed to enter his home country for the funeral. In telling about her travels, Milena constructs herself as full of emotions. She remembers the grief and pain as well as the happiness of being outside of her country for the first time. Then she focuses on her next positive experience in Norway - how she met her husband, which is told with a lot of passion:

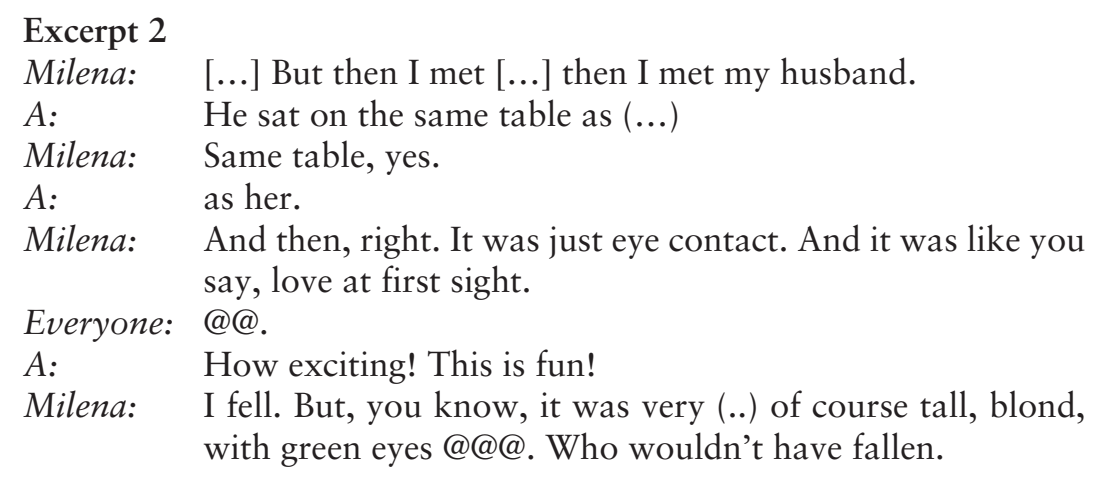

Milena's voice is almost ecstatic as she evaluates this first encounter with her future husband as something almost unreal. The audience's joy, expressed in laughter and co-construction of the story through questions and comments on details, shows that her stance in presenting the situation as romantic encountered appreciation. In contrast, Nadia's evaluation of her husband at least in retrospect - is different:

\section{Excerpt 3}

Nadia: I was a bit unlucky with [my] man, who was kind of (...) Looking at it now (..) a bit depressed and anti-social. [...] A guy who sits in front of the PC all the time. Yes, so everything that I achieved, it's like, it's just mine.

A: But did you get to know any Norwegians or others, then, in the beginning?

Nadia Those that I know, is through work.

In revealing this depressing situation, and her way out of it, Nadia constructs herself as independent, strong, and self-sufficient. 
Both Nadia and Milena went through difficulties and successes of different kinds while learning Norwegian. Their reactions also vary. Nadia describes how she experienced differences between her mother tongue and Norwegian, her knowledge of these languages, and the feedback she received from her husband:

\section{Excerpt 4}

Nadia: I don't know how it is in x-language (Milena's first language), but $x$-language has [a lot of] grammar, like y-language. In that way, Norwegian is much easier. And this was also difficult for me because I knew many, many words in my language. And it's very, very nuanced. X-language is very nuanced. [...] No fixed rule, it just has to adapt to time and gender.

A: $\quad$ Grammatical marking, yes. [...]

Milena: Oh dear.

A: And you miss that in Norwegian? You prefer.. @@@

Nadia: No, but I missed flexibility also when we started writing [...] essays in the Norwegian course [...] so I give it to my husband to correct it, [he] says like: "There are so many words here somehow, you can say just 'ninini'" (making a sound). (...) And for me: "No, but it will not be that nice." [He said:] "But this is sort of over-decorated," and I learned [...]

Although I tried to say, "Can you speak Norwegian to me?" [I] also try to speak in Norwegian. Then he says, "You are so very broken," so he thought he understood better if ...

When Nadia reports on how her husband evaluates her writing in Norwegian, she constructs him as someone who devalued her attempts to express herself in Norwegian in a way that she considers nuanced and nice. Both the researcher and Milena comment, question, tease, and laugh, which spurs Nadia to continue elaborating on how she had to unlearn the style of x-language to sound Norwegian, and how her husband was unwilling to speak Norwegian to her. In her story Nadia uses direct speech, and thus allows the focus group participants into her story-world. For example, she narrates her husband's comment that she is "so very broken" ("så veldig gebrokken"), which means he will have difficulty understanding her when she talks Norwegian. The Norwegian adjective "gebrokken" has a negative connotation (as opposed to having an accent). Her husband's utterance might be interpreted as an instance of "iconization" (Irvine and Gal 2000, 37), which links linguistic forms to a social phenomenon: he does not want to listen to her "conspicuous foreignness" (40). Nadia constructs him as unaffected by or unaware of her feelings and her struggle. She reveals how all of these obstacles led her to not speak Norwegian for a long period: 


\section{Excerpt 5}

Nadia: But I could not speak the first three years.

A: $\quad$ You found speaking the most difficult?

Nadia: Actually, yes, I had a blocking here. I was so unsure how I (...) It was like, I started to understand dialects. I understood everything, in a way. I watched TV, understand everything; listen to radio, understand everything. But I was not able to perform, to get it out.

By calling it a "blocking," she points to a serious psychological diagnosis. Second language anxiety has been vividly discussed in the literature (Macintyre 2017). In particular, classroom speaking is reported to be the most affected by anxiety. Lately, researchers have pointed to the need for "[a]dding a narrative component to our understanding of language anxiety" as "[1]earner stories can be re-narrated, which in turn can affect the whole tenor of the anxious self" (Şimşek and Dörnyei 2017, 66). Furthermore, Nadia tells that she worked with a voice recorder in class, listening to herself and then re-recording her voice, which helped her through the "blocking." She eventually gained more confidence in her competence. In this way, she constructs herself as both vulnerable to her husband's criticism and her own perception of otherness, but also agentive and empowered in her ways of overcoming these obstacles.

Milena tells about her experience in a very different way. She claims that, for her, the most difficult period in learning Norwegian was when she did not understand people. But her husband provided feedback and support. Milena constructs him as very caring. However, she declares that the "best compliment" she ever received was when a patient evaluated her Norwegian, saying: "I thought you came from Northern Norway. You speak dialect, see." To sound like a "Norwegian" seems to be the target of many learners. Research indicates that there exists a stereotypical notion of 'Norwegianness' that is connected to language practice, such as the use of a local dialect (Mesthrie, Opsahl and Røyneland, Chapter 3 in this volume; Røyneland and Jensen 2020).

When the researcher asks Nadia if she has had a similar experience, she claims that her psychological boost happened when she was (re-)constructed as a doctor by her teacher:

\section{Excerpt 6}

Nadia: We started talking just a bit and asking "What are you doing?" or "Who are you?" Like that. Then I said, "I was a doctor." She then corrects me, the teacher: "You are a doctor." "Yes, I was a doctor." "But you're still a doctor." And it was like that (...) It was real, [I] remember it was such a psychological boost. I'm actually that - once a doctor, always a doctor. 
Receiving the correction that she still is a doctor helps her to construct herself, not just as a pitiful person unable to speak the language, but rather as someone with resources and with all of the knowledge a doctor possesses. Later she constructs herself as somebody who has developed over time in Norway, moving from struggling emotionally when asked for clarifications to accepting her way of speaking. " $[\mathrm{O}] \mathrm{k}$, I'm a foreign doctor, I can make small mistakes like that communicatively." Norwegians' once upsetting requests for repetition or their questions about her origins and how she likes it in Norway are no longer felt as threatening. Rather, she considers them as a type of Norwegian small talk, not primarily meant to position her as a foreigner or as somebody who does not belong.

Various aspects of the narratives of Milena and Nadia trigger understanding and reveal different representations of the self that would not have been apparent through statistics, questionnaires, or sample interviews. As immigration is a process that critically involves a continuous definition and redefinition of one's identity, we see how the two doctors construct different identities in the story-world. As they position themselves as both vulnerable and agentive, included and excluded, clever and not so clever, they are sometimes almost contradictory. The analysis of learners' narratives uncovers the centrality of emotions in language learning. The participants use feelings to represent their life experiences, and the two narrators point to emotions and support as being fundamental elements in successful learning experiences. Their openness is likely due to the context. A small, informal focus group allows for and encourages comments and reactions, which provides rich opportunities for support and reassurance from the other participants. The participants' engagement in telling their stories is evident. Storytelling gives them a means to reflect on the process of immigration as well as on language learning, as highlighted by Milena's suggestion to name the narrative study Scheherazade.

\section{Conclusion}

In this chapter we have presented different ways in which narrative as a research tool and as an instrument for analyzing talk can be used to illuminate aspects of migrant identities. We have exemplified our views through two different projects: one focused on narratives posted online by Dreamers, a movement of young, undocumented migrants in the United States; and a second centered on learners of Norwegian interviewed in a focus group. We have argued that both types of studies, which have in common a storytelling-as-practice orientation, show how narrative analysis allows for a deeper understanding of phenomena related to migration, particularly in the study of identity. Indeed, the picture that emerged from the analysis of the identities constructed by narrators pointed to complex and contradictory constructions, always highly contextualized within specific practices and interactions. In the first case, Dreamers were shown to 
have developed strategic collective self-presentations that were in line with the need to respond to political circumstances and attuned to the imagined audiences addressed through their stories. We also saw that identities and their interpretations are shaped by a variety of factors at different scales. As the analyst goes from a level of generality that involves collective selfrepresentations to greater specificity, many new facets of identity start to become visible, thus offering a nuanced understanding of the experience of being an undocumented youth in the United States. In the second case, we discussed how identities are co-constructed and negotiated in focus groups and how the analysis of talk provides insights at different levels. From the perspective of the interactional level, we showed how the learners negotiated different degrees of agency and different inventories of identities with the researcher, and the researcher contributed to that construction by aligning with them and showing understanding. From the point of view of the construction of knowledge about the learning process, the narrative analysis demonstrated the emotionally charged nature of the migrants' experiences, how people close to migrants may have a pivotal role in their development as learners, and the kinds of experiences that appear to define different learners' trajectories. Migration is one of the landmark events in the lives of individuals and groups. Without input from immigrants regarding their realities, it is hardly possible to understand this process. Narratives about the learners' trajectories divulge information about migrants' experiences in a way that resonates with researchers' meaningmaking capacity as well as displaying the power that voicing experiences has to shape and transform individual and collective realities.

In brief, the study of stories, and particularly the focus on storytelling as practice, leads to reflections on how identities are constructed and performed by migrants in relation to specific contexts of communication. It fosters a heightened awareness of the need to attend to different storytelling arenas in order to capture the complexity of migrants' experiences. Indeed, in the face of discourses - mainstream and academic - that reduce migrants and transnational individuals to an amorphous and homogenous mass, narratives reveal the variety of inventories of identities that may be relevant to these individuals and groups in different circumstances. What they say and show about themselves as well as how they say it is tightly imbricated with interlocutors, listeners, personal histories, and public moments. Summing up, we have shown that narrative analysis provides a point of entry into nuanced and context-sensitive understandings of migrants identities viewed as complex, individualized, and emergent.

\section{Transcription conventions}

(.) (..) (...) Pause

? Question intonation

[...] Deleted single word when marked in a turn or deleted utterances when marked between turns 
[word] Text added by transcriber for the ease of understanding

@ Laughter

Bold Emphasis

“” $\quad$ Reported speech

(( )) Transcriber's comment

\section{Acknowledgments}

We wish to express our gratitude to the editors of the volume, Robert Blackwood and Unn Røyneland, and to Alexandra Georgakopoulou for their insightful comments on an early draft of this article. This work was partly supported by the Research Council of Norway through its Centers of Excellence funding scheme, project number 223265.

\section{Notes}

1 The transcription of the story from the 2015 Corpus is based on intonation units, while stories from the 2017 Corpus are presented in their original arrangement.

2 Elizabeth Lanza at the University of Oslo led the SKI project, and Anne Golden participated and collected data in several focus groups with adult migrants, mainly doctors. Golden had previously met the doctors at a venue for international doctors, where she had lectured on the Norwegian language. Data from two of the focus groups have been analyzed in several studies (Golden and Lanza 2013a, 2013b, 2019). Data for the present study was also collected within the SKI project but in another focus group with participants other than those from the mentioned studies by Golden and Lanza.

3 Securing the doctors' anonymity in a Norwegian context restricts us from giving further background information.

4 All of the citations as well as the excerpts were translated from Norwegian by the authors.

\section{References}

Alexandra, Darcy. 2008. "Digital Storytelling as Transformative Practice: Critical Analysis and Creative Expression in the Representation of Migration in Ireland." Journal of Media Practice 9, no. 2: 101-112.

Archakis, Argiris. 2016. "National and Post-National Discourses and the Construction of Linguistic Identities by Students of Albanian Origin in Greece." Multilingua 35, no. 1: 57-83.

Bakhtin, Mikhail. 1981. The Dialogic Imagination. Austin, TX: University of Texas Press.

Bamberg, Michael. 1997. "Positioning between Structure and Performance." Journal of Narrative and Life History 7, no. 1-4: 335-342.

Baran, Dominika. 2018. "Narratives of Migration on Facebook: Belonging and Identity among Former Fellow Refugees." Language in Society 47, no. 2: 245-268.

Barkhuizen, Gary. 2013. "Maintenance, Identity and Social Inclusion Narratives of an Afrikaans Speaker Living in New Zealand." International Journal of the Sociology of Language 2013, no. 222: 77-100. 
Baynham, Mike. 2006. "Performing Self, Family and Community in Moroccan Narratives of Migration and Settlement." In Discourse and Identity, edited by Anna De Fina, Deborah Schiffrin, and Michael Bamberg, 376-397. Cambridge: Cambridge University Press.

Blommaert, Jan. 2015. "Chronotopes, Scales and Complexity in the Study of Language in Society." Annual Review of Anthropology 44: 105-16.

Blommaert, Jan, and Anna De Fina. 2017. "Chronotopic Identities: On the Spacetime Organization of Who We Are." In Diversity and Superdiversity: Sociocultural Linguistic Perspectives, edited by Anna De Fina, Didem Ikizoglu, and Jeremy Wegner, 1-15. Washington, DC: Georgetown University Press.

Blommaert, Jan, and Piia Varis. 2015. "Enoughness, Accent and Light Communities: Essays on Contemporary Identities." Tilburg Papers in Culture Studies, paper 139. https://www.tilburguniversity.edu/research/institutes-and-research-groups/ babylon/tpcs/itempaper-139-tpcs.htm.

Busch, Brigitta, and Mikhal Krzyanowski. 2012. "Media and Migration: Exploring the Field.” In Migrations: Interdisciplinary Perspectives, edited by Michi Messer, René Schroeder, and Ruth Wodak, 277-283. Vienna: Springer-Verlag.

Cederberg, Maja. 2014. "Public Discourses and Migrant Stories of Integration and Inequality: Language and Power in Biographical Narratives.” Sociology 48, no. 1: 133-149.

Charteris-Black, Jonathan. 2006. "Britain as a Container: Immigration Metaphors in the 2005 Election Campaign.” Discourse \& Society 17, no. 5: 563-581.

Clary-Lemon, Jennifer. 2010. “'We're not Ethnic, We're Irish!': Oral Histories and the Discursive Construction of Immigrant Identity." Discourse \& Society 21, no. 1: 5-25.

De Fina, Anna. 2003. Identity in Narrative: A Study of Immigrant Discourse. Amsterdam: John Benjamins.

De Fina, Anna. 2009. "Narratives in Interview - The Case of Accounts. For an Interactional Approach to Narrative Genres." Narrative Inquiry 9, no. 2: 233-258.

De Fina, Anna. 2015. "Narrative and Identities." In Handbook of Narrative Analysis, edited by Anna De Fina and Alexandra Georgakopoulou, 351-368. Hoboken, NJ: Wiley-Blackwell.

De Fina, Anna. 2021. "Doing Narrative Analysis from a Narratives-as-Practices Perspective." Narrative Inquiry. Special Issue on Methodology of Narration: What the First Thirty Years of Narrative Inquiry Has Revealed. 31 (1): 49-71.

De Fina, Anna. 2020. "Biography as a Political Tool: The Case of the Dreamers." In Sociolinguistic Perspectives on Migration Control:Language Policy, Identity and Belonging, edited by, Markus Rheindorf, and Ruth Wodak, 64-85. Bristol: Multilingual Matters.

De Fina, Anna, and Alexandra Georgakopoulou, eds. 2008. "Introduction: Narrative Analysis in the Shift from Texts to Practices." Text and Talk, 28, no. 3: 275-281.

De Fina, Anna, and Kendall King. 2011. "Language Problem or Language Conflict? Narratives of Immigrant Women's Experiences in the US.” Discourse Studies, 13 (2): 163-188.

De Fina, Anna, and Sabina Perrino, eds. 2011. "Narratives in Interviews, Interviews in Narrative Studies.” Special Issue, Language in Society 40. 
De Fina, Anna, and Amelia Tseng. 2017. "Narrative in the Study of Migrants.” In Routledge Handbook of Language and Migration, edited by Suresh Canagarajah, 381-395. New York: Routledge.

Denzin, Norman. 1989. Interpretive Biography. Newbury Park, CA: Sage.

Evers, Cécile. 2018. “Alienated at Home: The Role of Online Media as Young Orthodox Muslim Women Beat a Retreat from Marseille." In Multilingual Youth Practices in Computer Mediated Communitation, edited by C. Cutler and U. Røyneland, 27-51. Cambridge: Cambridge University Press.

Gabrielatos, Costas, and Paul Baker. 2008. "Fleeing, Sneaking, Flooding: A Corpus Analysis of Discursive Constructions of Refugees and Asylum Seekers in the UK Press 1996-2005." Journal of English Linguistics 36, no. 1: 5-38.

Golden, Anne, and Elizabeth Lanza. 2013a. "Metaphors of Culture: Identity Construction in Migrants' Narrative Discourse." Intercultural Pragmatics 10, no. 2: 295-314.

Golden, Anne, and Elizabeth Lanza. 2013b. "Narratives on Literacies: Adult Migrants' Identity Construction in Interaction." In Literacy Practices in Transition: Perspectives from the Nordic Countries, edited by Anne PitkänenHuhta and Lars Holm, 27-54. Bristol: Multilingual Matters.

Golden, Anne, and Elizabeth Lanza. 2019. Language Learning and Literacy: The Multilingual Subject in Narratives of Older Immigrant Refugee Women. In Reconceptualizing Connections between Language, Literacy and Learning, edited by Sangeeta Bagga-Gupta, Anne Golden, Lars Holm, Helle Pia Laursen, and Anne Pitkanen-Huhta, 253-276. Cham: Springer Nature.

Gotsbachner, Emo. 2001. "Xenophobic Normality: The Discriminatory Impact of Habitualized Discourse Dynamics.” Discourse \& Society 12, no. 6: 729-759.

Hatoss, Anikó. 2012. “'Where Are You From?' Identity Construction and Experiences of 'Othering' in the Narratives of Sudanese Refugee-Background Australians." Discourse \& Society 23, no. 1: 47-68.

Irvine, Judith, and Susan Gal. 2000. "Language Ideology and Linguistic Differentiation.” In Regimes of Language: Ideologies, Polities, and Identities, edited by Paul Kroskrity, 35-83. Santa Fe, NM: School of American Research Press.

Kalaja, Paula, and Ana Maria Ferreira Barcelos. 2003. Beliefs about SLA. New York: Springer.

Kanno,Yasuko. 2003. Negotiating Bilingual and Bicultural Identities: Japanese Returnees Betwixt Two Worlds. Mahwah, NJ: Lawrence Erlbaum Associates.

Kramsch, Claire. 2009. The Multilingual Subject. Oxford: Oxford University Press

Liebscher, Gabrielle, and Jennifer Dailey-O’Cain. 2006. “West Germans Moving East: Place, Political Space, and Positioning in Conversational Narratives." In Dislocations/Relocations: Narratives of Displacement, edited by Mike Baynham and Anna De Fina, 61-85. Manchester: St. Jerome.

Macintyre, Peter D. 2017. "An Overview of Language Anxiety Research and Trends in Its Development." In New Insights into Language Anxiety: Theory, Research and Educational Implications, edited by Christina Gkonou, Mark Daubney, and Jean-Marc Dewaele, 11-30. Bristol: Multilingual Matters.

Mesthrie, Rajend, Toril Opsahl and Unn Røyneland. "Contesting Stereotypes: Language, Colour, and Identity - Northern and Southern Perspectives," this volume, chapter 3 . 
Miller, Elizabeth. 2014. The Language of Adult Immigrants: Agency in the Making. Bristol: Multilingual Matters.

Mortensen, Janus, and Spencer Hazel. 2017. "Lending Bureaucracy Voice: Negotiating English in Institutional Encounters." In Changing English, edited by Markku Filppula, Juhani Klemola, Anna Mauranen, and Svetlana Vetchinnikova, 255-276. Berlin: De Gruyter.

Nekvapil, Jirí. 2003. "Language Biographies and the Analysis of Language Situations: On the Life of the German Community in the Czech Republic.” International Journal of the Sociology of Language 165: 63-83.

Nicholls, Walter. 2013. The Dreamers. Stanford, CA: Stanford University Press.

Norton Peirce, Bonny. 1995. "Social Identity, Investment, and Language Learning." TESOL Quarterly 29, no. 1: 9-31.

Norton Peirce, Bonny, and Margaret Early. 2011. "Researcher Identity, Narrative Inquiry, and Language Teaching Research.” TESOL Quarterly 45, no. 3: 415-439.

Norton Peirce, Bonny, and Kelleen Toohey. 2011. "Identity, Language Learning, and Social Change." Language Teaching 44, no. 4: 412-446.

Pastor, Ana Maria Relaño. 2014. Shame and Pride in Narrative: Mexican Women's Language Experiences at the U.S.-Mexico Border. New York: Palgrave Macmillan.

Pavlenko, Aneta. 2001. "How Am I to Become a Woman in an American Vein?" In Second Language Learning, Multilingualism, and Gender, edited by Aneta Pavlenko, Adrian Blackledge, Ingrid Piller, and Marya Teutsch-Dwyer, 133-174. Berlin: Mouton De Gruyter.

Pavlenko, Aneta, ed. 2006. Bilingual Minds: Emotional Experience, Expression, and Representation. Clevedon: Multilingual Matters.

Pavlenko, Aneta. 2007. “Autobiographic Narratives as Data in Applied Linguistics.” Applied Linguistics 28, no. 2: 163-188.

Pavlenko, Aneta. 2013. "The Affective Turn in SLA: From 'Affective Factors' to 'Language Desire' and 'Commodification of Affect'”. In The Affective Dimension in Second Language Acquisition, edited by Danuta Gabrys-Barker and Joanna Bielska, 3-28. Bristol: Multilingual Matters.

Pavlenko, Aneta, and James Lantolf. 2000. "Second Language Learning as Participation and the (Re)construction of Selves." In Sociocultural Theory and Second Language Learning, edited by James Lantolf, 155-177. Oxford: Oxford University Press.

Perrino, Sabina. 2019. "Narrating Migration Politics in Veneto, Northern Italy." Narrative Culture 1, no. 6: 44-68.

Prior, Matthew. 2011. 'I'm Two Pieces Inside of Me': Negotiating Hybridity and Belonging through L2 Narratives." In Negotiating the Self in Another Language: Identity Formation and Cross-Cultural Adaptation in a Globalized World, edited by Christina Higgens, 27-47. New York: De Gruyter Mouton.

Røyneland, Unn, and Bård U. Jensen. 2020. "Dialect Acquisition and Migration in Norway - Questions of Authenticity, Belonging and Legitimacy." Journal of Multilingual and Multicultural Development. 1-17. doi: 10.1080/0143463 2.2020 .1722679

Sabaté i Dalmau, Maria. 2015. "Migrant Identities in Narrative Practice: In-/ Out-Group Constructions of 'Comrades' and 'Rivals' in Storytelling about Transnational Life.” Narrative Inquiry 25, no. 1: 91-112. 
Simmons, Katie, and Amanda Le Couteur. 2008. "Modern Racism in the Media: Constructions of the Possibility of Change in Accounts of Two Australian Riots." Discourse \& Society 19, no. 5: 667-687.

Şimşek, Erdi, and Zoltàn Dörnyei. 2017. “Anxiety and the L2 Self-Image: The Anxious Self." In New Insights into Language Anxiety Theory, Research and Educational Implications, edited by Christina Gkonou, Mark Daubney, and Jean-Marc Dewaele, 51-69. Bristol: Multilingual Matters.

Van de Mieroop, Dorien. 2012. "The Discursive Construction of Gender, Ethnicity and the Workplace in Second Generation Immigrants' Narratives: The Case of Moroccan Women in Belgium.” Pragmatics 22, no. 2: 301-325.

Van de Mieroop, Dorien, and Jonathan Clifton. 2012. "The Interactional Negotiation of Group Membership and Ethnicity: The Case of an Interview with a Former Slave." Discourse \& Society 23, no. 2: 163-183.

Yi, Youngjoo. 2009. "Adolescent Literacy and Identity Construction among 1.5 Generation Students from a Transnational Perspective." Journal of Asian Pacific Communication 19, no. 1: 100-129.

Zhu, Zhu. 2014. 'Making the 'Invisible' a 'Visible Problem' - The Representation of Chinese Illegal Immigrants in U.S. Newspapers." Journal of Chinese Overseas 10, no. 1: 61-90. 